\title{
III.-The Relation between the Products of Oxidation, and the Molecular Constitution of the Bodies Oxidized.
}

By E. T. Chapman and W. Thorp.

[Contribution from the Laboratory of the London Institution.]

\section{Part II.}

GuYcerin and mannite:- these two substances resemble each other in many particulars. They both yield iodides of secondary alcohol-radicals when treated with hydriodic acid. These iodides in both instances yield olefines when acted upon by alcoholic solution of potash. By oxidation these olefines yield acids of lower carbon-condensation than themselves. That obtained from mannite, $\beta$-hexylene, yields, as we have already shewn, propionic, acetic, and carbonic acids. The olefine from glycerin has been shewn by M. Truchot to yield acetic and formic acids; we have oxidized it and obtained acetic and carbonic acids.

It is well known that glycerin, when heated with caustic potash, yields acetic and formic acids. We have examined the reaction, and can confirm this statement.

These acids have the same carbon-condensation as those obtained from the corresponding olefine by oxidation. Mannite, when treated with caustic potash, yields propionic, acetic, and formic acids. The following experiments enable us to confirm this result. Thirty grammes of mannite were heated with caustic potash just moistened with water. The mixture melted, turned yellow, frothed up very much, and gave off inflammable gas; the contents of the dish were then dissolved in water, and distilled with excess of sulphuric acid. Formic acid was found in the distillate. A portion of the latter was converted into baryta-salt. Per centage of Ba from mixed salts, 52.83. The remainder of the distillate was neutralized with potash, evaporated to dryness, and gently warmed 
with concentrated sulphuric acid. Carhonic oxide was evolved.* The mixture was then diluted and distilled, and a portion of the distillate was converted into baryta-salts. Per cent. of $\mathrm{Ba}, 50 \cdot 11$, showing the presence of acetic acid, because the formic acid was destroyed, and no other acid yields a barium-salt containing more than 48.41 per cent. of barium. The remainder of the distillate was neutralized with standard solution of caustic potash, and divided into four fractions, the first three of one-fifth each, and the last of two-fifths. These different fractions were, as usual, converted into baryta-salts, and the percentages of barium they contained were determined.

\begin{tabular}{|c|c|c|c|c|}
\hline Substance taken. & $\begin{array}{l}\mathrm{Ba}_{-} \mathrm{SO}_{4} \\
\text { found. }\end{array}$ & $\begin{array}{l}\text { Per cent. } \\
\text { Ba found. }\end{array}$ & $\begin{array}{l}\text { Theoretical } \\
\text { per cent. }\end{array}$ & $\begin{array}{l}\text { Acid to which this } \\
\text { corresponds. }\end{array}$ \\
\hline $\begin{array}{c}\text { First fraction } \frac{3}{5} \\
3962 \\
\text { Second fraction } \frac{1}{5} \\
\cdot 3690 \\
\text { Third fraction } \frac{1}{5} \\
\cdot 4120 \\
\text { Fourth fraction } \frac{2}{5} \\
\cdot 5382\end{array}$ & $\begin{array}{l}\cdot 3249 \\
\cdot 3042 \\
\cdot 3440 \\
\cdot 4902\end{array}$ & $\begin{array}{l}48 \cdot 22 \\
48 \cdot 47 \\
49 \cdot 10 \\
53 \cdot 55\end{array}$ & $\begin{array}{c}48 \cdot 41 \\
, \\
\text { intermediate } \\
53 \cdot 725\end{array}$ & $\begin{array}{l}\text { Propionic } \\
\text { ", }\end{array}$ \\
\hline
\end{tabular}

Fractions 1 and 2 correspond closely enough with propionic acid. Fraction 3 corresponds to propionic acid contaminated with a trace of some lower acid, acetic of course; and fraction 4 corresponds to pure acetic acid. Thus mannite also yields to this treatment acids corresponding with those obtained by the oxidation of the olefine obtained from itself.

We now proceeded to oxidize glycerin and mannite with our ordinary oxidizing mixture, bichromate of potash and sulphuric acid. In both instances a most violent reaction occurs; carbonic acid is evolved abundantly, and formic acid produced. No other acid appears to be formed. The absence of other acids was proved by our ordinary process of fractionation, and by the fact that on converting a portion of the distillate in both instances into baryta-salts, and determining the percentage of barium, the numbers obtained agreed with those required by formic acid. The results of these two experiments, the treatment with caustic potash

* This treatment with concentrated sulphuric acid does not injure any acid of the acetic series, from acetic to caproic inclusive. 
and the process of direct oxidation, appear to be to a certain extent antagonistic. The latter process would lead one to believe that these two substances contain each atom of their carbon directly attached to hydroxyl and hydrogen.

We observed that mannite in acid solution decolorized permanganate of potash. It appeared therefore of interest to determine how much permanganate a given weight of mannite would decolorize. But as formic acid would probably be among the products of the action, we previously experimented on some formic acid, and found that permanganate can exist in the presence of formic acid for some hours without decomposition, provided the fluid be strongly acid with sulphuric acid. In neutral or alkaline solutions the permanganate is rapidly decolorized. If, therefore, formic acid be once produced, it would not be at once decomposed by the further action of permanganic acid.

Having ascertained the behaviour of formic acid, we proceeded to operate upon a sample of mannite in precisely the manner ordinarily employed in determining oxalic acid. At first, the solution decolorized somewhat slowly, exactly as in the case of oxalic acid; then the process rapidly quickened, and for some time the decolorization of the permanganate took place almost instantaneously; afterwards, longer and longer periods were required for the decolorization. When, after ten minutes' standing, the colour had not perceptibly decreased, the process was stopped. $0.36 *$ of mannite dissolved in dilute sulphuric acid decolorized $214 \mathrm{c}$. c. of permanganate of potash. $100 \mathrm{c.c}$. of the permanganate solution contained 0.094504 of available oxygen, therefore the mannite had required 0.20372 of oxygen. This corresponds to 92 per cent. of the amount of oxygen required to produce formic acid.

As there was so much difficulty in marking the completion of the reaction, and as the permanganate solution was much more rapidly decomposed when concentrated than when dilute, we devised a modification of the experiment. - More than sufficient permanganate of potash was introduced into a flask, along with dilute sulphuric acid, and a weighed quantity of mannite added. After ten minutes; oxalic acid was added in more than sufficient quantity to decolorize the excess of permanganate employed. Then the excess of oxalic acid was in its turn determined by per-

* 1.08 of mannite was dissolved in 150 c. c. of water, and $\frac{1}{3}$ of the solution em. ployed in each experiment. 
manganate. The result of this roundabout experiment was, that a little more oxygen was employed than would have been required if the whole of the mannite had been converted into formic acid.

0.36 of mannite, dissolved in dilute sulphuric acid, was treated with 300 c.c. of the above-mentioned permanganate solution. It was allowed to stand ten minutes. A known excess of oxalic acid was then added, which immediately caused the fluid to become colourless and clear. The amount of oxalic acid in the fluid was then determined by the addition of permanganate. It appeared that 238 c. c. of permanganate had been required by the mannite. Another such experiment was made, with the exception that the liquid was allowed to stand fifteen minutes before the addition of oxalic acid, instead of ten. In this case 241 c. c. of permanganate were required by the mannite.

From the first experiment, it appears that $102 \cdot 26$ per cent. of the amount of oxygen required to convert mannite into formic acid was actually consumed in the operation. In the second experiment, in which the action had been allowed to continue half as long again, 103.6 per cent. of the required amount of oxygen was actually consumed.

These differences between the numbers found and those calculated are very trifling, and are amply accounted for by the slow action of permanganate upon formic acid. In order that no doubt whatever might rest upon the subject, the formic acid was actually distilled out of the mixture remaining after these operations. From it were obtained the well-known actions of formic acid. A portion of it was converted into a baryta-salt and the percentage of barium determined.

0.3402 of the salt yielded 0.3468 of sulphate of baryta; therefore 59.93 per cent. of barium. Theoretical percentage, 60.30.

Therefore mannite is decomposed by nascent oxygen, thus :-

$$
\mathrm{C}_{6} \mathrm{H}_{14} \mathrm{O}_{6}+7 \mathrm{O}=6 \mathrm{CH}_{2} \mathrm{O}_{2}+\mathrm{H}_{2} \mathrm{O} \text {. }
$$

